\title{
A clinicopathological study of liver disease in haemophiliacs
}

\author{
P. M. MANNUCCI, G. RONCHI, LIDIA ROTA, AND M. COLOMBO \\ From the Haemophilia and Thrombosis Centre Angelo Bianchi Bonomi, and the 3rd Department of \\ Clinical Medicine, University of Milan, Via Pace 9, 20122 Milan, Italy
}

SUMMARY Chronic liver disease is not often reported in patients with haemophilia. Although a high incidence of abnormal liver function tests has been reported, the clinical significance of these findings and their relation to chronic liver disease cannot be established without a liver biopsy. The results of this procedure, carried out in 11 patients with severe haemophilia A and B, in whom SGOT had been persistently raised for three years, are reported. Five patients had chronic active hepatitis, four had chronic persistent hepatitis, one had cirrhosis, and one alcoholic hepatitis. No haemorrhagic complication followed the biopsy procedure, which was carried out in patients given prophylactic clotting factor concentrates. These results suggest that duration of abnormal liver function tests is likely to represent liver disease in haemophiliacs, and that biopsy should be considered to establish the diagnosis and plan a suitable therapeutic programme.

It has recently been shown that multitransfused haemophiliacs have a high incidence of abnormal liver function tests. According to different reports, 40 to $60 \%$ of patients have raised levels of serum transaminases whether or not there is a history of jaundice (Mannucci et al., 1975; Hasiba et al., 1977; Hilgartner and Giardina, 1977). Although the majority were asymptomatic and had no physical signs of liver disease, abnormal enzyme values may be the expression of chronic hepatitis. Since the clinical significance of these findings cannot be ascertained with single measurements, we have followed 66 severe haemophiliacs with serial determinations of liver function tests over a period of three years. In patients showing increased values of serum transaminases throughout the entire study period, histological examination of the liver was deemed necessary to assess the nature of the disease. Hence, percutaneous biopsy was carried out in 11 patients given prophylactic clotting factor concentrates, and the tissue specimens showed a high incidence of chronic active liver disease.

\section{Patients}

Liver function tests were carried out at yearly intervals from 1974 to 1976 in 66 patients (51 with severe haemophilia $A$ and 15 with severe haemophilia B) during regular follow-up visits at the Haemophilia Centre. Those patients who had serum aspartate

Received for publication 21 December 1977 aminotransferase (SGOT) above the upper normal limit $(20 \mathrm{mU} / \mathrm{ml})$ at all of the three visits were offered percutaneous liver biopsy after the benefits and risks of the procedure had been explained in detail. When consent had been obtained, patients were admitted to the hospital the day before biopsy. If no inhibitor to factor VIII or IX was found, patients with haemophilia A were treated with cryoprecipitate immediately before biopsy; patients with haemophilia B were similarly infused with a commercial prothrombin complex concentrate (Preconativ, Kabi, Stockholm). Dosage was calculated in order to increase the deficient clotting factor to $100 \%$ of normal immediately before the procedure, which was done using the Tru Cut ${ }^{R}$ needle (Travenol Laboratories, Rome). Additional replacement therapy was given after 12 hours in order to maintain factors VIII or IX at not less than $50 \%$ of average normal for the first 24 hours, and then at 24-hour intervals for the next four days, adjusting the dose to attain at any time levels of not less than $20 \%$. Patients were followed in hospital with routine haematological tests and then discharged if no complication occurred.

\section{Methods}

Factor VIII and IX assays were carried out before and 15 minutes after each therapeutic infusion with the methods described by Wilson et al. (1971). The presence ofinhibitors was checked by the method of Strauss and Merler (1967). 
The liver function tests performed were serum bilirubin, aspartate and alanine aminotransferase (SGOT and SGPT), gamma glutamyltranspeptidase $(\gamma \mathrm{GT})$, serum protein electrophoresis, and $\mathrm{HB}_{\mathbf{s}} \mathrm{Ag}$ and anti-HB (radioimmunoassays, Ausria and Ausab, Abbott Laboratories); the methods used have been described previously (Mannucci et al., 1975). Tissue nuclear, smooth-muscle, and mitochondrial antibodies were detected using an indirect fluorescent-antibody technique. All of the liver specimens were examined by two clinical hepatologists (GR and MC). The histological diagnosis of chronic persistent hepatitis and chronic active hepatitis was based on the criteria established by De Groote et al. (1968) and subsequently modified by the International Association for the Study of the Liver (Leevy, 1976).

\section{Results}

Liver function tests carried out three times at yearly intervals were available in 66 patients with severe haemophilia (factor VIII or IX less than $0.01 \mathrm{U} / \mathrm{ml}$ ). In 17 patients, SGOT was always found to be within the normal limits $(<20 \mathrm{mU} / \mathrm{ml})$. In 13 , the enzyme was increased on one occasion but was normal on the remaining two visits; in 16 , increased values were found in two instances and normal in one, whereas the remaining 20 patients showed persistently abnormal values. Three of them could not be considered for biopsy because an inhibitor was detected, six refused to undergo the procedure, and 11 accepted. All had received multiple infusions with various types of blood products (whole blood, cryoprecipitate, and commercial concentrates). Un- fortunately, a precise record of the total number of infusions was not always available in all the recipients. The Table summarises liver function tests carried out at the time of biopsy, the main clinical findings, and the histological features. Four patients (1-4) showed varying degrees of chronic persistent hepatitis (Fig. 1), five (5-9) had chronic active hepatitis, and patient 10 showed features of postnecrotic active cirrhosis. In two patients with chronic active hepatitis ( 7 and 8 ) the histological signs of the disease were mild (portal mononuclear infiltration associated with periportal necrosis); patients 5 and 6 showed a more severe picture with central-to-portal bridging necrosis, whereas patient 9 had clearcut features of transition to cirrhosis (Fig. 2). Patient 11 showed centrilobular and portal fibrosis with minimal mononuclear infiltration, and marked steatosis and siderosis; on the basis of these findings and a history of prolonged alcohol intake, a diagnosis of mild chronic alcoholic hepatitis was established. Only two patients (9 and 10) had in their history an episode of jaundice formerly diagnosed as acute hepatitis. Liver enlargement was found in patient $\mathbf{1 0}$ with cirrhosis, in patient 11 with alcoholic hepatitis and, to a lesser extent, in two patients (6 and 7) with chronic active hepatitis. In patients who eventually showed chronic active hepatitis at biopsy, liver function tests were usually more markedly impaired (higher transaminase and gamma globulin values) though the difference from those with chronic persistent hepatitis was not always clearcut. No treatment was prescribed for patients with chronic persistent hepatitis, who were advised to have liver function tests at more frequent intervals; patient 11 was asked to abstain from alcohol. Patients 6 and 7

Table Liver function tests, clinical features, and histological changes in 11 patients with severe haemophilia

\begin{tabular}{|c|c|c|c|c|c|c|c|c|c|c|}
\hline Case & $\begin{array}{l}\text { Age } \\
\text { (yr) }\end{array}$ & $\begin{array}{l}\text { Haemo- } \\
\text { philia }\end{array}$ & $\begin{array}{l}\text { Total } \\
\text { bilirubin } \\
(m g / d l)\end{array}$ & $\begin{array}{l}\text { SGOT } \\
(m U / m l)\end{array}$ & $\begin{array}{l}S G P T \\
(m U / m l)\end{array}$ & $\begin{array}{l}\gamma-g \text { lobulins } \\
(g / d l)\end{array}$ & $\begin{array}{l}\text { Tissue } \\
\text { antibodies }\end{array}$ & $H B \cdot A g$ & $\begin{array}{l}\text { Anti- } \\
\text { HB. }\end{array}$ & $\begin{array}{l}\text { Concentrate } \\
\text { exposure } \\
\text { (days) }\end{array}$ \\
\hline $\begin{array}{l}1 \\
2 \\
3 \\
4 \\
5\end{array}$ & $\begin{array}{r}18 \\
12 \\
11 \\
13 \\
7\end{array}$ & $\begin{array}{l}\mathbf{A} \\
\mathbf{B} \\
\mathbf{A} \\
\mathbf{B} \\
\mathbf{A}\end{array}$ & $\begin{array}{l}1 \cdot 1 \\
0 \cdot 4 \\
0 \cdot 4 \\
1 \cdot 1 \\
1 \cdot 2\end{array}$ & $\begin{array}{l}24 \\
31 \\
22 \\
67 \\
38\end{array}$ & $\begin{array}{r}9 \\
9 \\
5 \\
59 \\
6\end{array}$ & $\begin{array}{l}1 \cdot 4 \\
0 \cdot 9 \\
1 \cdot 1 \\
1 \cdot 3 \\
0.9\end{array}$ & $\begin{array}{l}- \\
- \\
- \\
-\end{array}$ & $\begin{array}{l}- \\
- \\
- \\
-\end{array}$ & $\begin{array}{l}+ \\
+ \\
+ \\
+ \\
+\end{array}$ & $\begin{array}{c}>200 \\
45 \\
100-150 \\
65 \\
78\end{array}$ \\
\hline 6 & 12 & $\mathbf{A}$ & 0.5 & 40 & 24 & $1 \cdot 6$ & - & - & + & $100-150$ \\
\hline $\begin{array}{l}7 \\
8 \\
9\end{array}$ & $\begin{array}{r}15 \\
6 \\
5\end{array}$ & $\begin{array}{l}\mathbf{A} \\
\mathbf{A} \\
\mathbf{A}\end{array}$ & $\begin{array}{l}0 \cdot 8 \\
0 \cdot 4 \\
1 \cdot 1\end{array}$ & $\begin{array}{r}46 \\
67 \\
103\end{array}$ & $\begin{array}{r}23 \\
9 \\
25\end{array}$ & $\begin{array}{l}2 \cdot 1 \\
1 \cdot 3 \\
1 \cdot 8\end{array}$ & $\begin{array}{l}- \\
-\end{array}$ & $\begin{array}{l}- \\
- \\
-\end{array}$ & $\begin{array}{l}+ \\
+ \\
+\end{array}$ & $\begin{array}{r}50-100 \\
<50>20 \\
100-150\end{array}$ \\
\hline 10 & 30 & $\mathbf{A}$ & $2 \cdot 6$ & 112 & 37 & $2 \cdot 5$ & - & - & + & $>200$ \\
\hline 11 & 47 & $\mathbf{B}$ & $1 \cdot 3$ & 22 & 186 & $1 \cdot 4$ & - & - & + & 56 \\
\hline \multicolumn{3}{|c|}{ Normal values } & $0.4-1 \cdot 0$ & 20 & 18 & $0 \cdot 7-1 \cdot 5$ & & & & \\
\hline
\end{tabular}

CPH = chronic persistent hepatitis $\mathbf{C A H}=$ chronic active hepatitis 


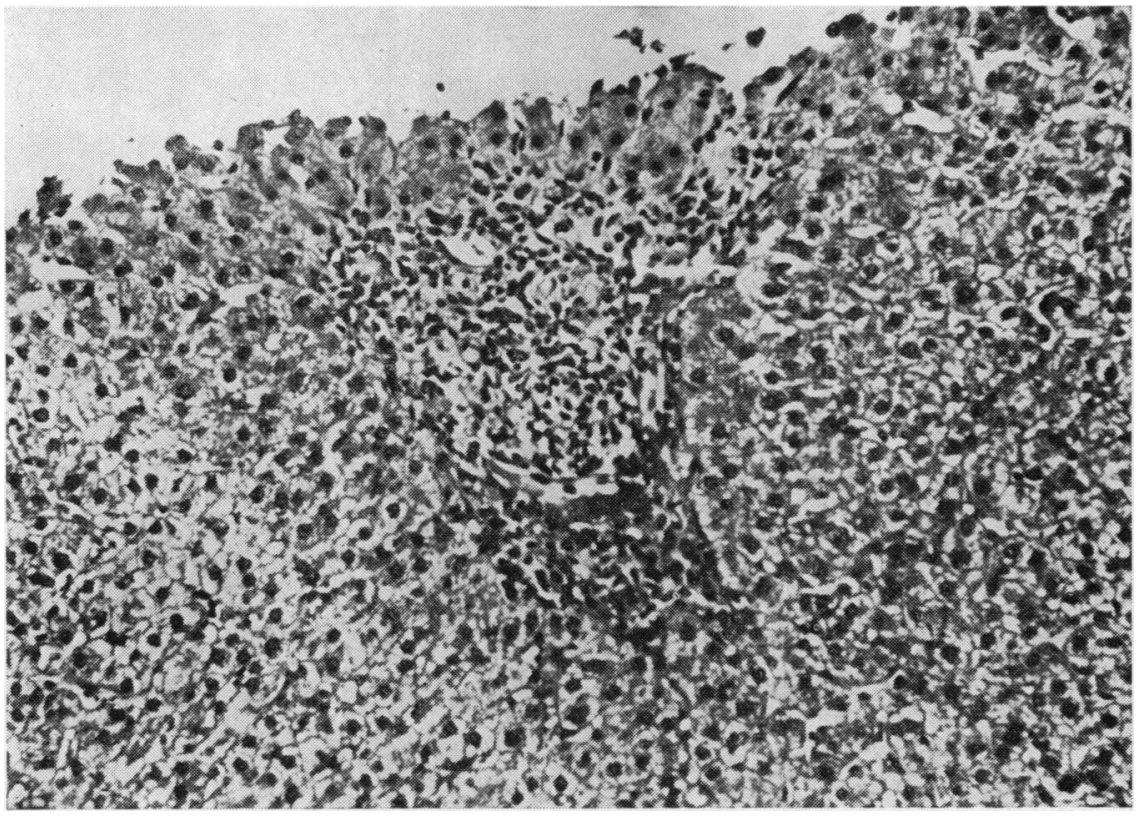

Fig. 1 Patient 1. Liver biopsy showing mononuclear infiltration of a portal tract. No piecemeal necrosis of the limiting plate.

Diagnosis: chronic persistent hepatitis. Haematoxylin and eosin $\times 65$.

with chronic active hepatitis as well as patient 10 are now on continuous oral treatment with 0.2 $0.3 \mathrm{mg} / \mathrm{kg}$ of prednisolone, which appears to be well tolerated. Treatment was followed by a marked improvement of subjective symptoms (fatigue and malaise) in all; SGOT returned to normal in patients 6 and 7, who are now on steroids for six and four months respectively, but it remained unchanged in patient 10 with cirrhosis. No specific treatment is now being given to the remaining three patients with chronic active hepatitis $(5,8,9)$ because it was thought that their ages and lack of symptoms would evolution of the hepatitis before any therapy could be started. This approach is tentative and will be reconsidered in the future according to the course of the disease.

\section{Discussion}

At the time of starting this study we hesitated before undertaking liver biopsy, which had not then been require a serial histological monitoring of the

lable-continued

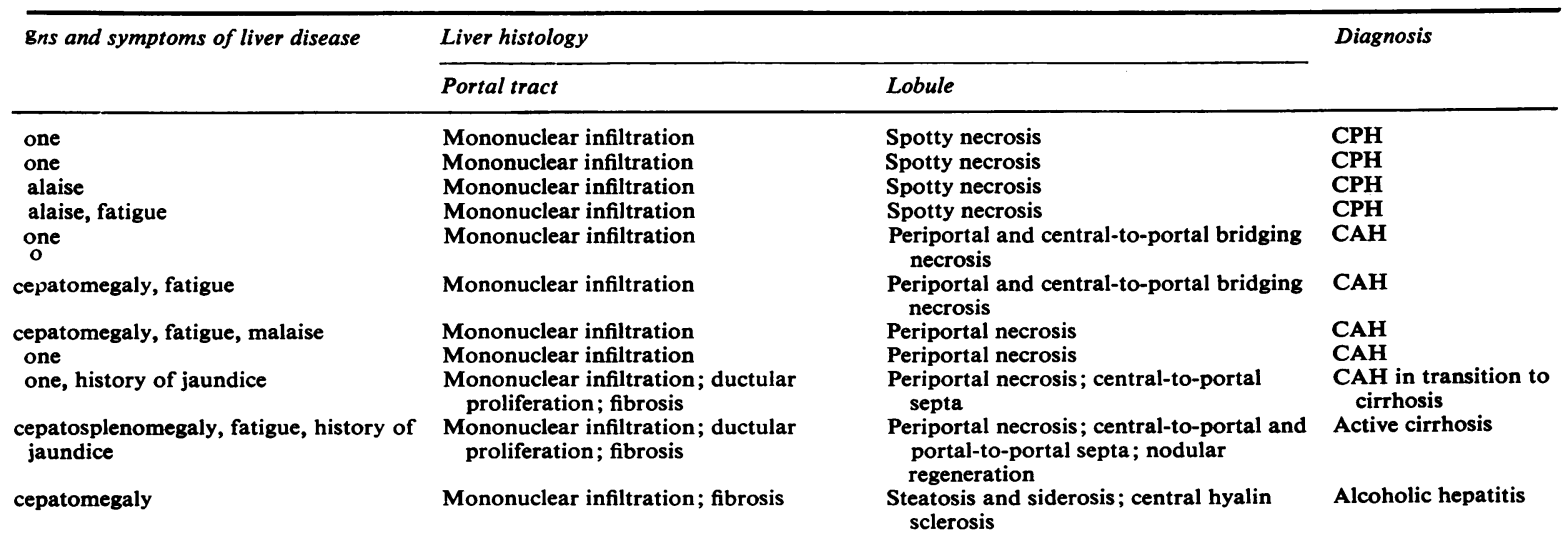




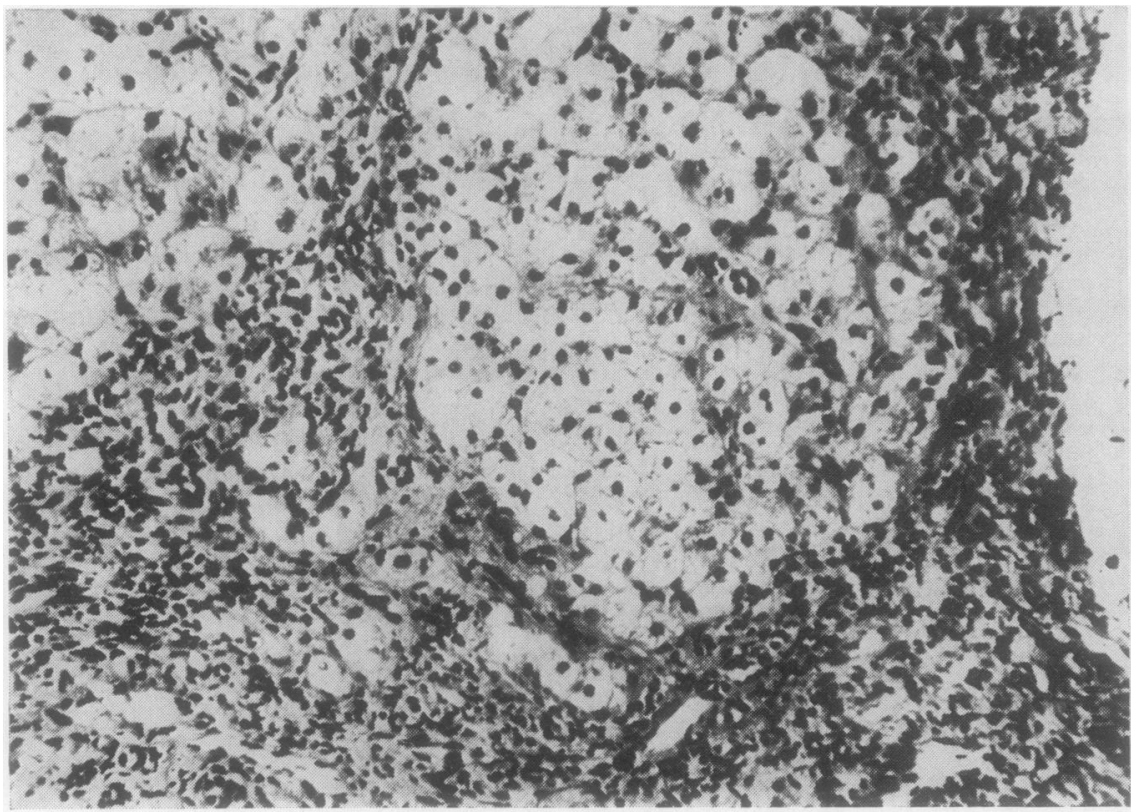

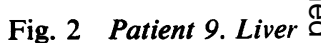
biopsy showing mononuclear infiltration of portal and periportal areas. Fibrous septa invade the parenchyma, showing acinar arrangement of the hepatocytes. Diagnosis: $\stackrel{\omega}{\vec{\omega}}$ chronic active hepatitis $\infty$ in transition to cirrhosis. $H$ and $E \times 130$

reported in haemophiliacs. There were the risks of a closed surgical procedure in patients with severe bleeding diathesis, as well as the high cost of replacement therapy needed to minimise such a risk. However, since the most difficult and traumatic operations are now being successfully carried out in haemophiliacs, it was thought that biopsy could be justified provided that the expected benefits outweighed the hazards. Several factors eventually supported this decision. Previous reports had shown that multitransfused haemophiliacs have a high incidence of mildly to moderately increased transaminases, but lack of information on the duration of such abnormalities left unsolved the problem of their clinical significance (Mannucci et al., 1975; Hasiba et al., 1977; Hilgartner and Giardina, 1977). Patients such as haemophiliacs, who are frequently exposed to the causative agents of hepatitis, are expected to mount a state of immunotolerance conditioning the development of a 'tolerating hepatitis' characterised by mild clinical expression and a favourable course (Grady, 1974; London et al., 1969). However, there is also evidence that chronic active hepatitis and cirrhosis may ensue even in the absence of (or in association with) minimal alterations of liver function tests (Grady, 1974; Simon and Patel, 1974; Woolf $e t$ al., 1974). Once it had been shown that in a number of patients SGOT remained increased for three years, histological examination became mandatory to define the nature and extent of the liver involvement.
In half of these patients, biopsy showed the presence of chronic active hepatitis which could not easily be predicted by liver function tests. The pathological features of chronic active hepatitis varied from minimal and potentially regressing $\triangle$ disease (patients 7 and 8 ) to obviously developing $\overrightarrow{\vec{O}}$ cirrhosis in case 9 (Fig. 2).

The incidence is similar to that in a very recent study by Lesesne et al. (1977), who found chronic active hepatitis in three out of six biopsies carried out in severe haemophiliacs. A peculiar feature of $\frac{}{\circ}$ our series is the younger age of the patients, whereas 3 the incidence of positive hepatitis B virus markers, of a history of jaundice, and of clinical symptoms of $\frac{}{3}$ liver disease is similar to that of Lesesne et al. (1977).

Since the natural history of chronic active 5 hepatitis is at present unknown and many clinical $\frac{}{8}$ trials of drug treatment are in progress (Summerskill et al., 1975; De Groote et al., 1976; Tygstrup et al., م 1976), no established therapeutic and prognostic guideline can be given at the moment in non- N haemophilic patients. Symptomatic and $\mathrm{HB}_{\mathrm{s}} \mathrm{Ag}-\omega$ negative patients seem to benefit from long-term? corticosteroid administration (Cook et al., 1971; ; Sherlock, 1974), although the hazards and side ${ }_{\infty}^{\Phi}$ effects of this treatment make it less advisable in asymptomatic patients. There is also preliminary ${ }^{\circ}$ evidence that the $\mathrm{HB}_{\mathrm{s}} \mathrm{Ag}$-positive subgroup fares $\frac{\mathrm{O}}{\mathrm{D}}$ worse with steroids (Schalm et al., 1976) but this $\stackrel{\odot}{\odot}$ contraindication must be confirmed in larger series $\varrho$ of patients. On the basis of this knowledge and of the? 
awareness that long-term steroid therapy carries a higher risk of gastrointestinal bleeding in haemophiliacs, we have chosen to avoid steroids in patients with chronic active hepatitis $(5,8,9)$ who were younger and asymptomatic; the natural history of the disease will be closely followed (by monitoring the evolution of the chemical and histological abnormalities) and a further biopsy might be carried out in the next few years. On the other hand, steroids were prescribed for patient 10 (with active cirrhosis) and for patients 6 and 7, who were symptomatic, $\mathrm{HB}_{\mathrm{s}} \mathrm{Ag}$-negative, and aged more than 10 years. It is at present difficult to assess any therapeutic benefit because the follow-up period is too short (4-12 months); there were no adverse symptoms or side-effects, the patients felt better, and SGOT showed a marked decrease in patients 6 and 7 (but not in patient 10 with cirrhosis).

If one assumes that significant liver disease was present only in patients with persistently increased transaminases and not in those showing sporadic elevation, its general incidence appears too small to justify withdrawal or limitation of concentrate administration in haemophiliacs. This would inevitably be accompanied by a consistent deterioration of their present pattern of life at a time when the natural history of chronic active hepatitis is unknown and a benign course cannot be ruled out. However, it is essential that those involved in haemophilia care become aware that liver disease is probably the most frequent 'secondary' disease in haemophilia and that liver function tests should be carried out at frequent intervals. Biopsy is advisable in patients who have persistent liver function test abnormalities and symptoms of liver involvement; a trial period of corticosteroids should be given to those with symptomatic, $\mathrm{HB}_{\mathrm{s}} \mathrm{Ag}$-negative chronic active hepatitis.

\section{References}

Cook, G. C., Mulligan, R., and Sherlock, S. (1971). Controlled prospective trial of corticosteroid therapy in active chronic hepatitis. Quarterly Journal of Medicine, 40, 159-185.

De Groote, J., Desmet, V. J., Gedigk, P., Korb, G., Popper, H., Poulsen, H., Scheuer, P. J., Schmid, M., Thaler, H., Uehlinger, E., and Wepler, W. (1968). A classification of chronic hepatitis. Lancet, 2, 626-628.

De Groote, J., Fevery, J., Verbrugghe, J., Desmet, V. J., and Vandenbroucke, J. (1976). Less active chronic hepatitis. A follow up of 59 patients. In Chronic Hepatitis, edited by P. Gentilini, H. Popper, and U. Teodori, p. 172. Karger, Basle and New York.

Grady, G. (1974). Tolerating hepatitis. New England Journal of Medicine, 291, 96-97.

Hasiba, U., Spero, H. A., and Lewis, J. H. (1977).
Chronic hepatitis in haemophilia. Scandinavian Journal of Haematology, Supplement, 30, 27-32.

Hilgartner, M. W., and Giardina, P. (1977). Liver dysfunction in patients with haemophilia. Scandinavian Journal of Haematology, Supplement, 30, 6-10.

Leevy, C. M. (Ed.) (1976). Disease of the liver and biliary tract with standardization of nomenclature, diagnostic criteria and diagnostic methodology. In Proceedings of the 5th Meeting of the International Society for the Study of the Liver, p. 172. Karger, Basle and New York.

Lesesne, H. R., Morgan, J. E., Blatt, P. M., Webster, W. P., and Roberts, H. R. (1977). Liver biopsy in hemophilia A. Annals of Internal Medicine, 86, 703-707.

London, W. T., Difiglia, M., Sutnick, A. I., and Blumberg, B. S. (1969). An epidemic of hepatitis in a chronichaemodialysis unit: Australia antigen and differences in host response. New England Journal of Medicine, 281, 571-578.

Mannucci, P. M., Capitanio, A., Del Ninno, E., Colombo, M., Pareti, F., and Ruggeri, Z. M. (1975). Asymptomatic liver disease in haemophiliacs. Journal of Clinical Pathology, 28, 620-624.

Schalm, S. W., Summerskill, W. H. J., Gitnick, G. L., and Elveback, L. R. (1976). Contrasting features and responses to treatment of severe chronic active liver disease with and without hepatitis $\mathrm{B}_{\mathrm{s}}$ antigen. Gut, 17, 781-786.

Sherlock, S. (1974). Chronic hepatitis. Gut, 15, 581-597.

Simon, J. B., and Patel, S. K. (1974). Liver disease in asymptomatic carriers of hepatitis B antigen. Gastroenterology, 66, 1020-1028.

Strauss, H., and Merler, E. (1967). Characterization and properties of an inhibitor of factor VIII in the plasma of patients with haemophilia $\mathbf{A}$ following repeated transfusions. Blood, 30, 137-150.

Summerskill, W. H. J., Korman, M. G., Ammon, H. V., and Baggenstoss, A. H. (1975). Prednisone for chronic active liver disease: dose titration, standard dose, and combination with azathioprine compared. Gut, 16, 876-883.

Tygstrup, N., Hoybye, G., Hilden, M., Dietrichson, O., Winkel, P., and Thomsen, A. O. (1976). Assessment of the therapeutic effect of prednisone and azathioprine in chronic active liver disease. In Chronic Hepatitis, edited by P. Gentilini, H. Popper, and U. Teodori, p. 117. Karger, Basle and New York.

Wilson, W. S., Ingram, G. I. C., and Hills, M. (1971). The use of kaolin or contact product in the one-stage assay of factor VIII. Coagulation, 4, 113-117.

Woolf, I. L., Boyes, B. E., Jones, D. M., Whittaker, J. S., Tapp, E., MacSween, R. N. M., Renton, P. H., Stratton, F., and Dymock, I. W. (1974). Asymptomatic liver disease in hepatitis B antigen carriers. Journal of Clinical Pathology, 27, 348-352.

Requests for reprints to: Prof P. M. Mannucci, International Training Centre Angelo Bianchi Bonomi of the World Federation of Haemophilia, 120122 Milan, Via Pace, 15, Italy. 